\title{
Organophosphate Poisoning in the Differential Diagnosis of Epileptic Seizures and Its Neuroradiological Features
}

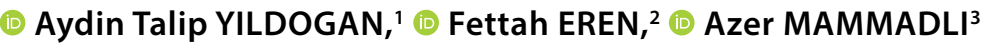 \\ 'Department of Neurology, Ersin Arslan Training and Research Hospital, Gaziantep, Turkey \\ ${ }^{2}$ Department of Neurology, University of Health Sciences, Konya City Hospital, Konya, Turkey \\ ${ }^{3}$ Department of Neurology, Selcuk University Faculty of Medicine Hospital, Konya, Turkey
}

\begin{abstract}
Organophosphate poisoning is a common form of suicide due to the widespread use of pesticides. A twenty-seven-year-old male patient presented with impaired consciousness, recurrent seizures and thick secretions in the mouth. The patient with frequent seizures and cholinergic findings was evaluated as compatible with organophosphate poisoning. Brain magnetic resonance imaging revealed symmetrical and bilateral lesions in the globus pallidus. The treatment of the patient whose epileptic seizures continued was rearranged. The possibility of poisoning should always be considered in the differential diagnosis of new-onset acute seizures and disorders of consciousness. Early recognition of poisoning, appropriate treatment and seizure control are important. Attention should also be paid to epileptic seizures after orgonaphosphate poisoning.
\end{abstract}

Keywords: Epileptic seizure; organophosphate; poisoning.

Cite this article as: Yildogan AT, Eren F, Mammadli A. Organophosphate Poisoning in the Differential Diagnosis of Epileptic Seizures and Its Neuroradiological Features. Epilepsi 2021;27:245-248.

\section{Giriş}

Akut semptomatik nöbetler metabolik, yapısal, enfeksiyöz, enflamatuvar ve toksik sebeplerden kaynaklanır. ${ }^{[1]}$ Toksinler sinir sistemindeki uyarılma ve inhibisyon dengesini değiştirerek veya enerji metabolizmasına müdahale ederek nöbetlere neden olur. ${ }^{[2]}$ Toksinlerin neden olduğu nöbetler, genellikle akut başlangıçlı jeneralize tonik-klonik konvülsiyonlar olarak ortaya çıkar. Tablo tekrarlayan nöbetlere ve status epileptikusa kadar ilerleyebilir. Toksine bağlı nöbetlerde, sorumlu toksik ajandan bağımsız olarak standart antikonvülsan tedavi yaklaşımı genellikle etkilidir. Ancak sorumlu toksinin erken teşhisi ve mevcut durumun tedavisi prognozu değiştirebilir. ${ }^{[3]}$ Zehirlenmelerin dünya genelinde yaygın nedenlerinden biri olan organofosfatlar da nöbetlere yol açabilir. ${ }^{[4,5]} \mathrm{Bu}$ yazıda bi-

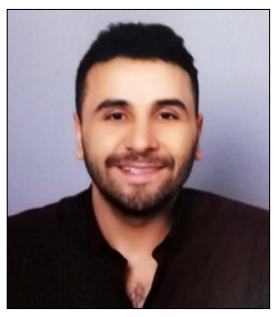

Corresponding author Aydin Talip YILDOGAN, M.D. e-mail yildoganaydintalip@gmail.com

Received 27.12.2020

Accepted 10.02.2021

Online date 09.11.2021

Content of this journal is licensed under a Creative Commons Attribution-NonCommercial 4.0 International License.

Aydin Talip YILDOGAN, M.D. linç bozukluğu ve tekrarlayan epileptik nöbetlerle başvuran bir organofosfat intoksikasyonu olgusu takdim etmekteyiz.

\section{Olgu Sunumu}

Kasım 2020'de, 27 yaşında erkek hasta bilinç bozukluğu, tekrarlayan kasılmalar ve aşırı ağız sekresyonları yakınmalarıyla acil servise getirildi. Hastanın tarlada çalıştıktan sonra yere yığıldığı ve bilinç bozukluğuyla acil servise getirildiği öğrenildi. Özgeçmişinde bilinen hastalık öyküsü yoktu. Nörolojik muayenesinde bilinci konfüze, pupiller bilateral miyotik olmakla beraber ışık refleksi azalmış olsa da alınabiliyordu. Derin tendon refleksleri tüm odaklarda hipoaktifti. Patolojik refleks saptanmadı. Hastanın solunum sıkıntısı ve artmış sekresyonları mevcuttu. Ayrıca idrar inkontinansı mevcuttu. Yüz bölgesi hiperemik ve terleme artışı mevcuttu. Hastanın kan basıncı 90/60 mmHg ve kalp hızı 52 atım/ dk idi.

Laboratuvar incelemelerinde lökosit: $20.010^{3} / \mathrm{mm}^{3}$ (3.510.5), hemoglobin: $17.5 \mathrm{~g} / \mathrm{dL}$ (13.5-17.5), platelet $22410^{3} /$ $\mathrm{mm}^{3}$ (150-450), uluslararası düzeltme oranı (INR): 1.07 (0.8-1.2), glukoz: $123 \mathrm{mg} / \mathrm{dL}$ (74-106), sodyum: $137 \mathrm{mEq} / \mathrm{L}$ (137-144), potasyum: $5.1 \mathrm{mmol} / \mathrm{L}$ (3.7-4.9), kalsiyum: 9.6 mg/dL (8.8-10.6) üre: 59 mg/dL (17-43), kreatinin: 1.02 mg/dL (0.81-1.44), AST: 276 U/L (0-50) ve ALT: 76 U/L (0- 


\section{Epileptik Nöbet Ayırıcı Tanısında Organofosfat İntoksikasyonu ve Nöroradyolojik Özellikleri}

Öz

Organofosfat zehirlenmesi, pestisitlerin yaygın kullanımı nedeniyle sık başvurulan bir suisit şeklidir. Yirmi yedi yaşında erkek hasta bilinç bozukluğu, tekrarlayan kasılmalar ve ağızda yoğun sekresyon nedeniyle başvurdu. Sık nöbetleri ve kolinerjik bulguları olan hasta organofosfat intoksikasyonu ile uyumlu olarak değerlendirildi. Beyin manyetik rezonans görüntülemede globus pallidusta simetrik ve bilateral lezyonlar saptandı. Epileptik nöbetleri devam eden hastanın tedavisi yeniden düzenlendi.. Yeni başlangıçlı akut nöbetlerin ve bilinç bozukluklarının ayırıcı tanısında intoksikasyon ihtimali her zaman göz önünde bulundurulmalıdır. İntoksikasyonun erken tanınması, uygun tedavi ve nöbet kontrolü sağlanması önemlidir. Orgonafosfat intoksikasyonu sonrası epileptik nöbet açısından da dikkatli olunmalıdır.

Anahtar sözcükler: Epileptik nöbet; intoksikasyon; organofosfat.

50) bulundu. Toraks bilgisayarlı tomografi (BT) ve idrar tetkiki normaldi. Beyin BT'de bilateral globus pallidusta hipodens alanlar izlendi (Şekil 1a). Difüzyon ağırlıklı manyetik rezonans görüntülemede (MRG) bilateral globus pallidusta difüzyon kısıtlılığı ile uyumlu sinyal değişikliği izlendi (Şekil 1b, c). Beyin omurilik sıvısı (BOS) glukoz seviyesi 89 mg/dL (40-70), eş zamanlı kan şekeri 123 mg/dL, BOS klor
$125 \mathrm{mg} / \mathrm{dL}$ (118-132), LDH $12 \mathrm{mg} / \mathrm{dL}$, mikroprotein 65.6 $\mathrm{mg} / \mathrm{DI}$ (15-45), potasyum $2.73 \mathrm{mg} / \mathrm{dL}$, sodyum $147 \mathrm{mg} /$ $\mathrm{dL}$ olarak sonuçlandı. BOS polimeraz zincir reaksiyon test sonucu normaldi. Elektroansefalografide (EEG) zemin ritmi düzensizdi. Sağ arka bağlantılarda voltaj asimetrisi- sola göre daha yüksek amplitüdlü yavaş dalgalar saptandı (Şekil 1d).
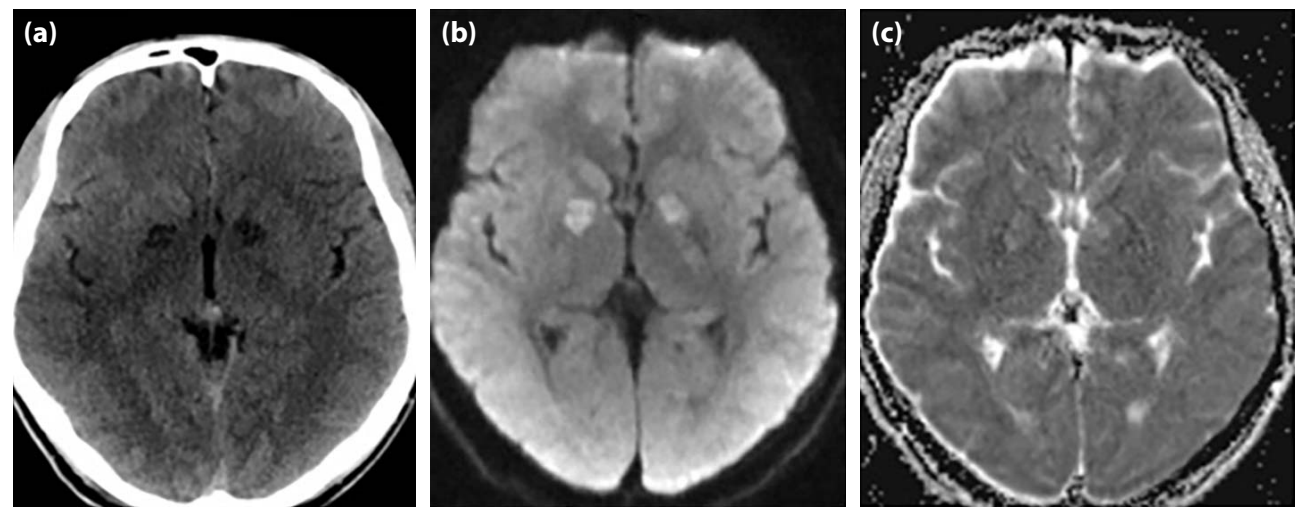

Şekil 1. (a) Beyin bilgisayarlı tomografi: Bilateral globus pallidusta hipodens alanlar. (b) Difüzyon ağırlıklı manyetik rezonans görüntüleme. (c) ADC haritalaması: Bilateral globus palliduslarda difüzyon kısıtııı̆ı ile uyumlu sinyal değişikliği. (d) Sağ arka bağlantılarda voltaj asimetrisi- sola göre daha yüksek amplitüdlü yavaş dalgalar.
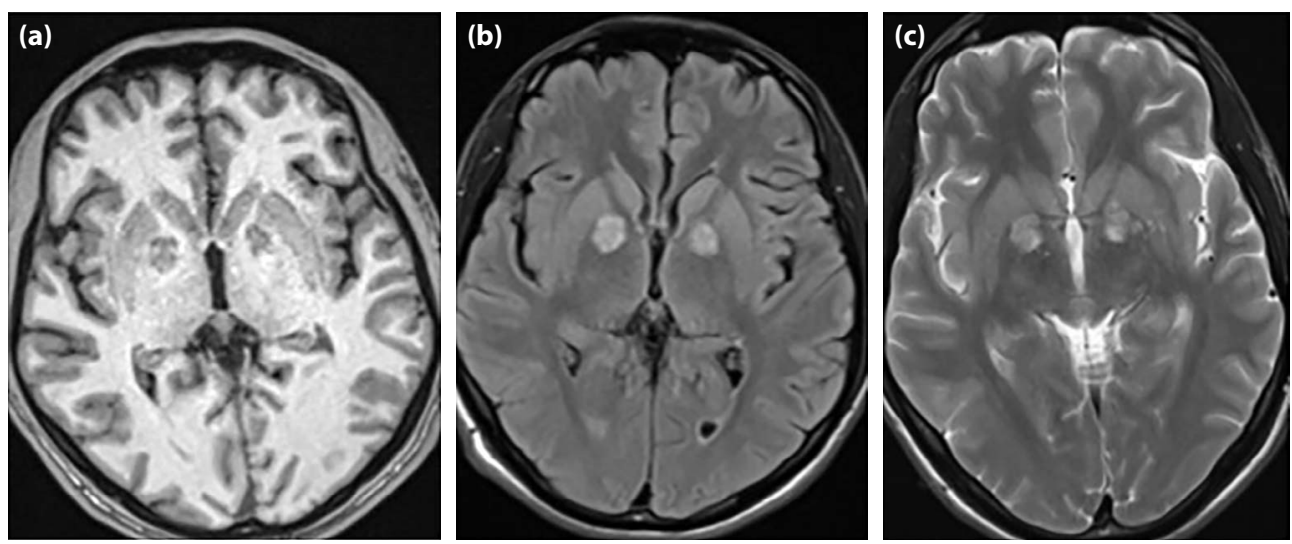

Şekil 2. (a) (T1 sekans), (b) (FLAIR sekans), (c) (T2 sekans): Beyin manyetik rezonans görüntüleme: bilateral globus pallidusta T1 sekansta hipointens, T2 ve FLAIR sekanslarda hiperintens lezyonlar. 
Hasta yakınlarından detaylı alınan anamnez sonrası hastanın tarlada çalışırken suisid amacı ile tarım ilacı içtiği öğrenildi. Mevcut durumun ve beyin lezyonlarının orgonafosfat (OP) ile ilişkili olabileceği düşünüldü. Hastaya atropin tedavisi uygulandı. Atropin $2 \mathrm{mg}$ bolus verildi ardından saatte $2 \mathrm{mg}$ infüzyon olarak devam edildi. Klinik cevaba göre dozajlama yapıldı. Üç günde hastanın durumunda kademeli düzelme oldu. Levetirasetam 1000 mg/gün başlandı. Nöbet kontrolü sağlandı. Hastanın taburculuk sonrası iki kez sekonder jeneralize olan tonik ve klonik vasıfta nöbetleri görülmesi tekrar başvurdu. Hastanın tekrarlanan EEG'sinde frontal bölgelerde daha belirgin hafif bilateral jeneralize yavaş dalga aktivitesi mevcuttu. Epileptiform dalga anormalliği izlenmedi. Tekrar çekilen (organofosfat intoksikasyonundan 20 gün sonra) beyin MRG'de bilateral globus pallidusta T2 ve FLAIR sekanslarda hiperintens, T1 sekansda hipointens tutulum mevcuttu (Şekil 2a-c). Levetirasetam aşamalı olarak 1000 mg/günden 2000 mg/güne çıkıldı. Nöbet kontrolü sağlanan hasta hafif konfüze olarak taburcu edildi.

\section{Tartışma}

Jeneralize nöbet aktivitesi ciddi toksisitenin öncü bir belirtisi olabilir. Izoniazid (INH), karbonmonoksit, teofilin, siklik antidepresanlar ve salisilatlar gibi çok sayıda ilaç ve toksinden kaynaklanabilir. Ayrıca, etanol ve sedatif hipnotik ajanlar gibi geri çekilme sendromu yapan durumlar da refrakter nöbet aktivitesini indükleyebilir. İlaç ve toksinle ilişkili nöbetler, çok çeşitli ajanlara maruziyetten kaynaklanabilir. Maruziyet ihtimalini göz önünde bulundurup kapsamlı bir anamnez almak genellikle tanısal testlerden daha faydalıdır.

Spesifik klinik tablolar, akut başlangıçlı nöbetlerle gelen olgularda ayırıcı tanının daraltılmasına yardımcı olabilir. Nöbet aktivitesinden önce gelen sempatomimetik bir toksidrom, kokain, amfetamin maruziyetine veya uyuşturucu madde yoksunluğuna işaret edebilir. Psikiyatrik geçmişi olan hastalar antidepresan, lityum veya karbamazepin gibi ajanları içerebilen kendi psikiyatrik ilaçlarından aşırı doz almış olabilir. Yakın zamanda alınmış pürifiye protein derivesi testi öyküsü veya göğüs radyografisinde kaviter lezyon izoniazid maruziyetinin ipucu olabilir. Elektrokardiyogramda genişlemiş QRS aralığı siklik antidepresanlar, propoksifen, venlafaksin, difenhidramin veya diğer ajanların maruziyetiyle ilişkili olabilir. ${ }^{[6]}$ Tarım alanında çalışma öyküsü olan ve kolinerjik bir toksidrom organofosfat intoksikasyonuyla ilişkili olabilir. ${ }^{[7]}$

Zehirlenmelerin dünya genelinde yaygın nedenlerinden biri olan organofosfatlar insektisit, medikasyon ve sinir gazı olarak kullanılan ajanlardır. ${ }^{[4,8]}$ Yılda yaklaşık 3 milyon zehirlenmeye sebep olmakta ve bu vakaların \%15'i ölümle sonuçlanmaktadır. ${ }^{[4,9]}$ Zehirlenme çoğunlukla istemli yutma, soluma veya deri yoluyla emilimle meydana gelir. Toksisite,nadiren intramüsküler veya intravenöz yoldan kendi kendine enjeksiyonla da ortaya çıkabilir. İntihar amaçlı yutma yaygın bir yöntem olmasına rağmen, tarım alanlarında ilaçlama sırasında mesleki maruziyet de önemli bir zehirlenme yöntemidir. Bizim olgumuzda suisit amaçIı tarım ilacı içme söz konusuydu. OP intoksikasyonunun klinik görünümü ve sonucu sadece pestisite değil, aynı zamanda doza, uygulama yoluna ve zehirlenme ile tedavinin başlaması arasındaki zamana da bağlıdır. ${ }^{[10]}$ Organofosfat kaynaklı akut toksisite, kolinerjik belirtilerin baskınlığıyla kendini gösterir. Akut kolinerjik toksisitenin belirgin klinik özellikleri bradikardi, miyozis, lakrimasyon, hipersalivasyon, ishal, bronkokonstriksiyona bağlı hırıltılı solunum, bronşiyal sekresyon, terleme, peristaltizm ve ürinasyonda artıştır. OP'lerin nörolojik komplikasyonları arasında, kas zayıflıkları, fasikülasyonlar, paralizi, anksiyete, ajitasyon, konfüzyon, konvülsiyonlar ve koma bulunur. ${ }^{[1]}$ Bu bileşiklerin etki mekanizmasının, asetilkolinesterazın geri dönüşümsüz inhibisyonuyla sinir sinapslarında asetilkolinin birikmesi ve nöbet aktivitesinin (konvülsiyonlar) uyarılması şeklinde olduğu düşünülmektedir. Bu durum, uyarıcı nörotransmitterlerin varlığı ile birleştiğinde beyindeki NMDA reseptörlerini aktive eder ve sonunda status epileptikusa yol açar. ${ }^{[12]}$ Organofosfat zehirlenmesinin karakteristik bir belirtisi olan flask paralizi konvülsiyonları maskeleyebileceğinden, nöbetlerin en güvenilir göstergesi elektroensefalogramdır. ${ }^{[1]}$ Bizim olgumuzda da bradikardi, miyozis, hipersalivasyon, solunum sıkıntısı, terleme artışı, konvulsiyon ve koma durumu mevcuttu. ${ }^{[13]}$ Akut organofosfat intoksikasyonundan kurtulanlar, hafıza ve dikkat bozukluğu, kişilik değişiklikleri ve parkinsonizm gibi kalıcı olabilecek nörodavranışsal kusurlara sahip olabilir. Bizim olgumuzda da hafıza ve dikkat bozukluğu mevcuttu. Bu nörobilişsel etkilerin, organofosfatların doğrudan nörotoksisitesinden mi kaynaklandığı yoksa hipoksi ve hastalığın diğer spesifik olmayan ciddi etkileriyle mi ilişkili olduğu açık değildir. ${ }^{[1]}$ OP'nin üç iyi tanımlanmış nörolojik sendroma neden olduğu bilinmektedir. Birincisi bilişsel bozukluk, konvülsiyonlar veya komanın mevcut olabileceği ilk kolinerjik kriz. İkincisi proksimal kas güçsüzlüğünün, kraniyal sinir felçlerinin ve solunum kaslarının zayıflı̆ının görüldüğü ara sendrom. Üçüncüsü genellikle baldır ve distal kas güçsüzlüğü, düşük ayak veya pençe el olarak prezente olan gecikmiş organofosfat kaynaklı polinöropatidir. ${ }^{[13]}$ OP zehirlenmesi tanısı, yutma öyküsü veya mukokutanöz maruziyet, klinik özellikler ve düşük plazma kolinesteraz seviyeleriyle konur. OP zehirlenmesi tanısında eritrosit kolinesteraz seviyesi daha spesifiktir. ${ }^{[10]}$ Bizim olgumuzda da OP yutma öyküsü ve OP intoksikasyonunu düşündürecek klinik bulgular vardı. Kolinesteraz inhibisyonuna bağlı şiddetli kolinerjik krizin spesifik yönetimi, antidot olarak atropin ve pralidoksi- 
min intravenöz uygulanması, sıvılar ve elektrolitlerle destekleyici bakımdır. ${ }^{[12]}$ Atropin, muskarinik reseptör aracılı etkileri antagonize ettiği için fizyolojik bir panzehir görevi görür. Atropin, başlangıç yükleme dozu 2-5 miligram $(\mathrm{mg})$ olarak verilir ve atropinizasyon belirtileri görülene kadar her 5-10 dakikada (dk) bir tekrarlanır. Bundan sonra 0.02-0.08 mg/ $\mathrm{kg} / \mathrm{dk}$ hızında infüzyon olarak verilir ve klinik cevaba göre doz titre edilir. Pralidoksim genellikle 6-8 saatte bir 1 gram (g) dozunda kullanılır. Son çalışmalarda 18-24 g/gün yüksek doz infüzyon ile daha iyi sonuçlar alındığı bildirilmiştir. ${ }^{[10]}$ OP intoksikasyonunda, beyin görüntüleme bulguları genel olarak ara sendrom sırasında ortaya çıkar ve haftalar içinde geri dönüşlü hale gelir. Beyin MRG'de bazal ganglionun simetrik ve bilateral tutulumu görülebilir. Wilson hastalığı, Hallervorden-Spatz, metilmalonik asidemi gibi metabolik hastalıklar, hipoksik beyin hasarı, emboli, metanol, siyanür, karbonmonoksit ve toluen gibi toksinler de simetrik bazal gangliyon tutulumuna neden olabilir. ${ }^{[14]}$ OP intoksikasyonunda özellikle putamen ve kaudat çekirdekler ağırlıklı olarak etkilenebilir. Genelde MRG'deki tüm sinyal değişikleri aylar içerisinde tamamen düzelir; diğer toksik ensefalopatilerin aksine kistik sekel bırakmaz. ${ }^{[14,15]}$ Bizim olgumuzun MRG'sinde de globus pallidusun simetrik ve bilateral olarak tutulumu mevcuttu. Bizim olgumuzda da beyin görüntüleme bulguları ara sendrom sırasında mevcuttu. Ayrıca bizim olgumuzda $\mathrm{OP}$ intoksikasyonunun ilk günündeki difüzyon ağırlıklı MRG de bilateral globus palliduslarda difüzyon artışı ile uyumlu sinyal değişikliği mevcuttu.

Sonuç- Sonuç olarak yeni başlangıçlı akut nöbetlerin ve bilinç bozukluklarının ayırıcı tanısında organofosfat intoksikasyonu her zaman dikkate alınmalıdır. Çünkü spesifik tedavi prognozu olumlu yönde etkileyebilir

Informed Consent- Written informed consent was obtained from patients who participated in this study.

Peer-review- Externally peer-reviewed.

Authorship Contributions- Concept: A.T.Y.; Design: A.T.Y., F.E.; Supervision: A.T.Y., F.E.; Data collection \&/or processing: A.T.Y., A.M., F.E.; Analysis and/or interpretation: A.T.Y., F.E.; Literature search: A.T.Y., A.M., F.E.; Writing: A.T.Y.; Critical review: A.T.Y., A.M., F.E.

Conflict of interest- The authors declare that they have no conflict of interest.

Financial Disclosure: The authors declared that this study has received no financial support.

Hasta Onamı- Bu çalışmaya katılan hastalardan yazılı hasta onamı alındı.

Hakem Değerlendirmesi- Dış bağımsız.
Yazarlık Katkıları- Konsept: A.T.Y.; Dizayn: A.T.Y., F.E.; Kontrol: A.T.Y., F.E.; Veri Toplama veya İşleme: A.T.Y., A.M., F.E.; Analiz ve Yorumlama: A.T.Y., F.E.; Literatür Arama: A.T.Y., A.M., F.E.; Yazan: A.T.Y.; Kritik revizyon: A.T.Y., A.M., F.E.

Çıkar Çatışması- Yoktur.

Finansal Destek- Yazarlar bu çalışma için finansal destek almadıklarını beyan etmişlerdir.

\section{Kaynaklar}

1. Beghi E, Carpio A, Forsgren L, Hesdorffer DC, Malmgren K, Sander JW, et al. Recommendation for a definition of acute symptomatic seizure. Epilepsia 2010;51(4):671-5. [CrossRef]

2. O'Brien D. Toxic and metabolic causes of seizures. Clin Tech Small Anim Pract 1998;13(3):159-66. [CrossRef]

3. Cendes F. Seizures attributable to environmental toxins. Seizures. Amsterdam: Springer; 2002:193-206. [CrossRef]

4. Eddleston M, Buckley NA, Eyer P, Dawson AH. Management of acute organophosphorus pesticide poisoning. Lancet 2008;371(9612):597-607. [CrossRef]

5. Rump S. Convulsions in organophosphate intoxications: Their mechanism and treatment. NBC Risks Current Capabilities and Future Perspectives for Protection. Amsterdam: Springer; 1999:189-95. [CrossRef]

6. Wills B, Erickson T. Chemically induced seizures. Clin Lab Med 2006;26(1):185-209, ix. [CrossRef]

7. Robb EL, Baker MB. Organophosphate Toxicity. 2021 Jul 26. In: StatPearls. Treasure Island (FL): StatPearls Publishing; 2021.

8. King AM, Aaron CK. Organophosphate and carbamate poisoning. Emerg Med Clin North Am 2015;33(1):133-51. [CrossRef]

9. Berg S, Bittner EA. The MGH Review of Critical Care Medicine. Philadelphia: Lippincott Williams \& Wilkins; 2013.

10. Pandit V, Seshadri S, Rao SN, Samarasinghe C, Kumar A, Valsalan R. A case of organophosphate poisoning presenting with seizure and unavailable history of parenteral suicide attempt. J Emerg Trauma Shock 2011;4(1):132-4. [CrossRef]

11. El Sayed Abdel Fattah I, Abdel Kader AA, Fayed AM, Abdelmonem $S$. Non convulsive status epileptics in a child with acute organophosphorus poisoning: a case report. MOJ Clin Med Case Rep 2016;4(5):120-1. [CrossRef]

12. Waheed S, Sabeen A, Ullah Khan N. New onset refractory status epilepticus as an unusual presentation of a suspected organophosphate poisoning. Case Rep Emerg Med 2014;2014:676358.

13. Phatake R, Desai $S$, Lodaya M, Deshpande S, Tankasali N. Posterior reversible encephalopathy syndrome in a patient of organophosphate poisoning. Indian J Crit Care Med 2014;18(4):250-2. [CrossRef]

14. Ravikanth R. Role of magnetic resonance imaging in diagnosing neurological complications in intermediate syndrome of organophosphate poisoning. Indian J Crit Care Med 2017;21(2):105-7. [CrossRef]

15. Panda AK, Bala K, Bhirud LJCR. Extrapyramidal syndrome. BMJ Case Rep 2014;2014:bcr2013009752. [CrossRef] 